\title{
Biomechanical Properties of the Cranial Dura Mater with Puncture Defects : An In Vitro Study
}

\author{
Hasan Emre Aydın, ${ }^{1}$ Ceren Kızmazoglu, ${ }^{2}$ Ismail Kaya, ${ }^{1}$ Bugra Husemoglu, ${ }^{3}$ Gulden Sozer, ${ }^{4}$ Hasan Havitcıoglu, ${ }^{3}$ Ali Arslantas ${ }^{5}$ \\ Department of Neurosurgery, Kutahya Health Science University, Kutahya, Turkey \\ Department of Neurosurgery, ${ }^{2}$ Dokuz Eylul University School of Medicine, Izmir, Turkey \\ Department of Biomechanics, ${ }^{3}$ Dokuz Eylul University School of Medicine Health Science Institute, Izmir, Turkey \\ Department of Pathology, ${ }^{4}$ Forensic Medicine Institution, Izmir, Turkey \\ Department of Neurosurgery, Eskişehir Osmangazi University School of Medicine, Eskisehir, Turkey
}

Objective : The primary aim of this investigation was to explore the nature of dura mater biomechanics following the introduction of puncture defect(s).

Methods : Twenty-eight dura mater specimens were collected during autopsy from the department of forensic medicine of the authors' institution. Specimens were divided randomly into one of four groups : group I (cranial dura mater; $n=7$ ), group II (cranial dura mater with one puncture defect; $n=7$ ); group III (cranial dura mater with two puncture defects; $n=7$ ), and group IV (cranial dura mater with three puncture defects; $\mathrm{n}=7$ ).

Results : The mean \pm standard deviation tensile strengths of the dura mater were $8.35 \pm 3.16,8.22 \pm 3.32,7.13 \pm 1.77$, and $6.94 \pm 1.93$ MPa for groups I, II, III, and IV, respectively. There was no statistical difference between all groups. A single, two or more punctures of the dura mater using a 20-gauge Quincke needle did not affect cranial dura tensile strength.

Conclusion : This biomechanical study may contribute to the future development of artificial dura mater substitutes and medical needles that have a lower negative impact on the biomechanical properties of dura mater.

Key Words : Biomechanical phenomena · Dura mater · Tensile strength · Punctures · Needles.

\section{INTRODUCTION}

The dura mater is a thick fibrous membrane that envelops the arachnoid mater and comprises fibroblasts and extracellular collagen. Although spinal dura mater is primarily arranged in a longitudinal orientation, the cranial dura mater is thicker and possesses isotropic viscoelastic properties ${ }^{2,14,17,23)}$. The dura mater is a viscoelastic material that resists high strain and plays a vital role, besides the cerebrospinal fluid, in protecting sensitive areas of the brain and spinal cord from impact ${ }^{17,25,26)}$. Although the dura mater protects brain parenchyma, it may be affected by trauma, iatrogenic causes (e.g., surgery and lumbar puncture) and/or tumour invasion. Post-dural puncture headache is an iatrogenic condition attributed to the

- Received : June 14, 2018 •Revised : July 31, 2018 •Accepted : September 1, 2018

- Address for reprints : Ceren Kizmazoglu

Department of Neurosurgery, Dokuz Eylul University School of Medicine, 35340 Balçova, Izmir 35000, Turkey

Tel : +90-232-412-33-01, Fax : +90-232-412-97-97, E-mail : ceren.kizmazoglu@gmail.com, ORCID : https://orcid.org/0000-0001-6146-0842

This is an Open Access article distributed under the terms of the Creative Commons Attribution Non-Commercial License (http://creativecommons.org/licenses/by-nc/4.0) which permits unrestricted non-commercial use, distribution, and reproduction in any medium, provided the original work is properly cited. 
leakage of cerebrospinal fluid into the epidural space. Reportedly, low cerebrospinal fluid pressure and cerebral vasodilatation are the two major mechanisms underlying this type of headache ${ }^{1,8,9)}$. In addition, the estimated incidence of post-dural puncture headache is $1.5-8.1 \%^{4,10,20)}$. Several clinical studies have reported that needle diameter, needle type and number of failed puncture attempts play a critical role in the development of post-dural puncture headache $\mathrm{h}^{10,13,18)}$.

The recent few years have witnessed an upsurge in interest in dura mater biomechanics; however, little research has been conducted to investigate the various biomechanical aspects of lumbar dura mater biomechanics after puncture ${ }^{7}$. Lately, a novel cone-shape microneedle array has been designed and tested in the porcine cranial dura mater for the treatment of hydrocephalus ${ }^{16}$; this implant passes through the dura mater to ensure a channel for the flow of cerebrospinal fluid. Despite our best efforts, nonetheless, we could find no biomechanical study in the literature that reported on the cranial dura mater after puncture(s). Prompted by the lack of studies in this field, the present study aimed to investigate the nature of dura mater biomechanics following the introduction of puncture defect(s).

\section{MATERIALS AND METHODS}

\section{Study design and samples}

The present study was conducted at the Health Science Institute Biomechanics Laboratory. All the experimental procedures performed were approved by the Ethics Committee of the affiliated institution (Forensic Medicine Institution, reference number : 21589509/375). We obtained 28 fresh human cranial dura mater specimens from the Department of Forensic Medicine, which were randomly categorised into four groups as follows : group I (cranial dura mater, $n=7$ ), group II (cranial dura mater with one-puncture defect, $n=7$ ), group III (cranial dura mater with two-puncture defects, $n=7$ ), and group IV (cranial dura mater with three puncture defects, $n=7)$.

\section{Sample preparation}

We obtained 28 cranial dura mater specimens during autopsy from the right and left frontal regions of seven participants (three males, four females; mean age, $44.57 \pm 11.58$ years [range, 31-62]). Of note, all the specimens were fresh and not fixed with formalin. We excised the dura mater widely to prevent mechanical damage. Besides the freeze-thaw effect, refrigerant protection could result in significant variations in the mechanical response of tissues. Thus, in this study, all the specimens were frozen at the same cooling rate and were stored at $-20^{\circ} \mathrm{C}$; the frozen specimens were thawed at $4^{\circ} \mathrm{C}$ for 24 hours before performing the tests. Furthermore, the specimens were thawed at room temperature $\left(20-25^{\circ} \mathrm{C}\right)$ for 6 hours before mechanical testing.

A customised die was used to cut the samples from the human dura mater and other dura substitutes, followed by random distribution of the specimens into four groups as previously mentioned. We prepared all the samples according to the Japanese Industrial Standard (JISK6251-5 [2004]). This standard dumbbell-shaped model describes the shape of the elastic material to determine the tensile stress-strain properties by Japanese Standards Association. During insertion, a 20 $\mathrm{G}(0.812 \mathrm{~mm}) \times 90 \mathrm{~mm}$ Quincke spinal needle (Egemen International Inc., Izmir, Turkey) was used to create puncture defects (Fig. 1) in the tissue specimens. The insertion was automated with constant velocity, in which the bevel tip was parallel to the specimen (Fig. 2). Fig. 3 illustrates the puncture defects, with the dimensions and orientation of the dura mater samples.

Prior to testing, we measured and recorded the thickness of the samples using a digital caliper micrometer gauge (model number SS17DV150, Zhejiang, China). Thickness changes due

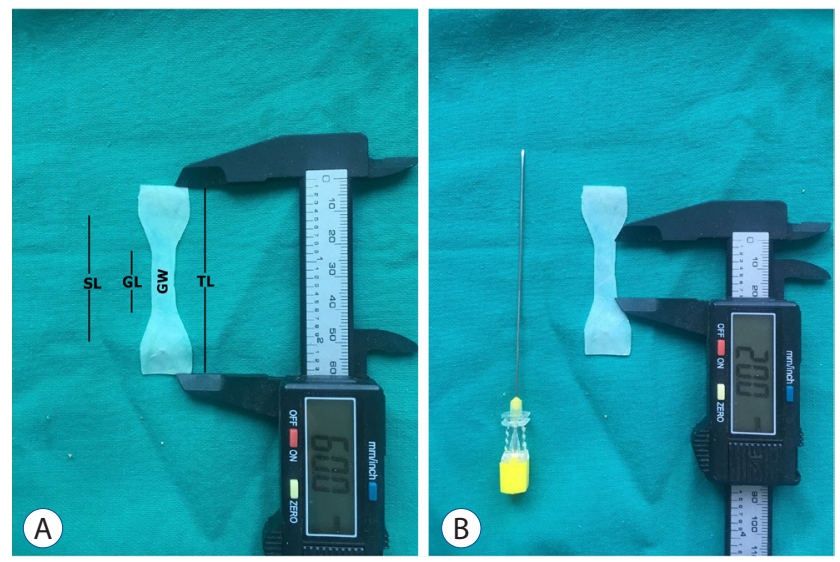

Fig. 1. A : Dimensions of the cranial dura mater specimens showing. B : Dimensions of the $20 \mathrm{G}$ Quincke needle (Egemen International Inc., Izmir, Turkey). SL : shoulder length, GL : gauge length, GW : gauge width, TL : total length. 
to specimens. A customised system was fabricated to simulate in vitro conditions. In addition, a customised cup was filled with artificial cerebrospinal fluid (sodium chloride $[\mathrm{NaCl}$, $134 \mathrm{mM}$; potassium chloride [KCl], $2.5 \mathrm{mM}$; magnesium chloride $\left[\mathrm{MgCl}_{2}\right], 1.3 \mathrm{mM}$; calcium chloride $\left[\mathrm{CaCl}_{2}\right], 2 \mathrm{mM}$; dipotassium hydrogen phosphate $\left[\mathrm{K}_{2} \mathrm{HPO}_{4}\right], 1.25 \mathrm{mM}$; sodium hydrogen carbonate $\left.\left[\mathrm{NaHCO}_{3}\right], 26 \mathrm{mM} \mathrm{D-glucose}\right)$ and heated to simulate physiological temperature $\left(37^{\circ} \mathrm{C}\right)$.

\section{Mechanical analyses}

We used an axial compression device (AG-IS 10 kN; Shimadzu Corporation, Kyoto, Japan) for mechanical analyses. Uniaxial tension was set according to JISK6251-5 standards, and the device was equipped with a $500-\mathrm{N}$ load cell. All the tests were performed at a displacement rate of $10 \mathrm{~mm} / \mathrm{min}$ at $36.91 \pm 0.36^{\circ} \mathrm{C}$ in a customised container filled with saline solution (Fig. 4). We recorded and assessed the mean maximum
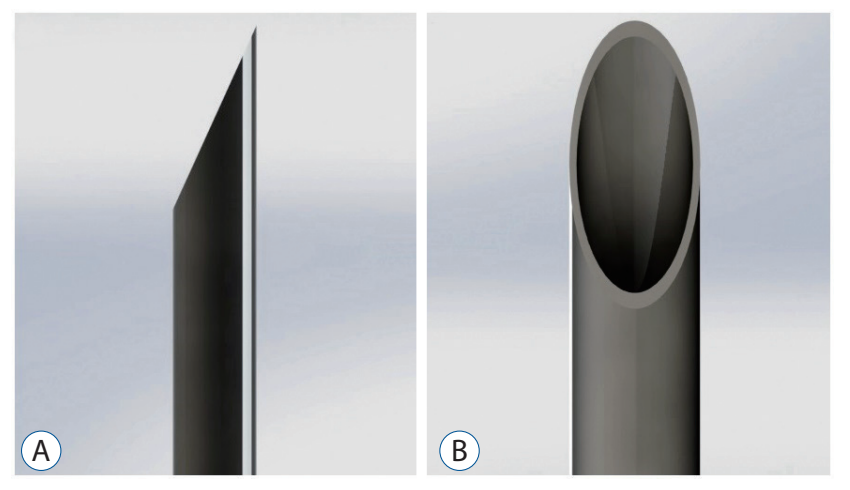

Fig. 2. A and $B$ : The bevel tip needle stylet and needle cannula. tensile strength using TRAPEZIUM X Materials testing software version 1.1.2 (Shimadzu Corporation). Hooke's law is commonly expressed in terms of normalized parameters by calculating stress. The tensile stress calculation by Hooke's law is as follows :

Hooke's equation - stress $(\mathrm{MPa})=\mathrm{P} / \mathrm{A}$

where $\mathrm{A}$ is the loaded cross-sectional area under tension and $\mathrm{P}$ is the loaded force in Newtons.

Young's modulus, or elastic modulus, is the measure of the elastic deformation of the material under force. Young's modulus is equal to the longitudinal stress divided by the strain.

\section{Statistical analysis}

We calculated the tensile strength and standard deviation values for the four groups. The mean tensile strength for each group was statistically analysed using the Mann-Whitney Utest using SPSS version 15.0 (SPSS, Chicago, IL, USA). In this

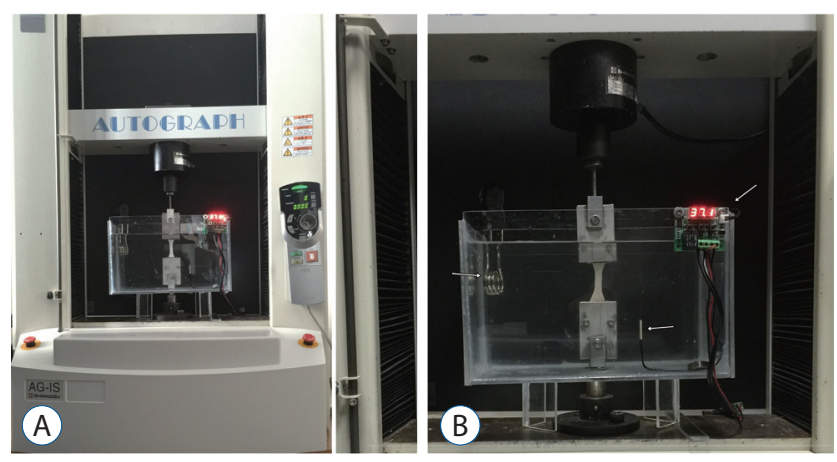

Fig. 4. The test setup ( $A$ ) and white arrows show (B, left to right) heating element, waterproof sensor, digital thermometer controller.
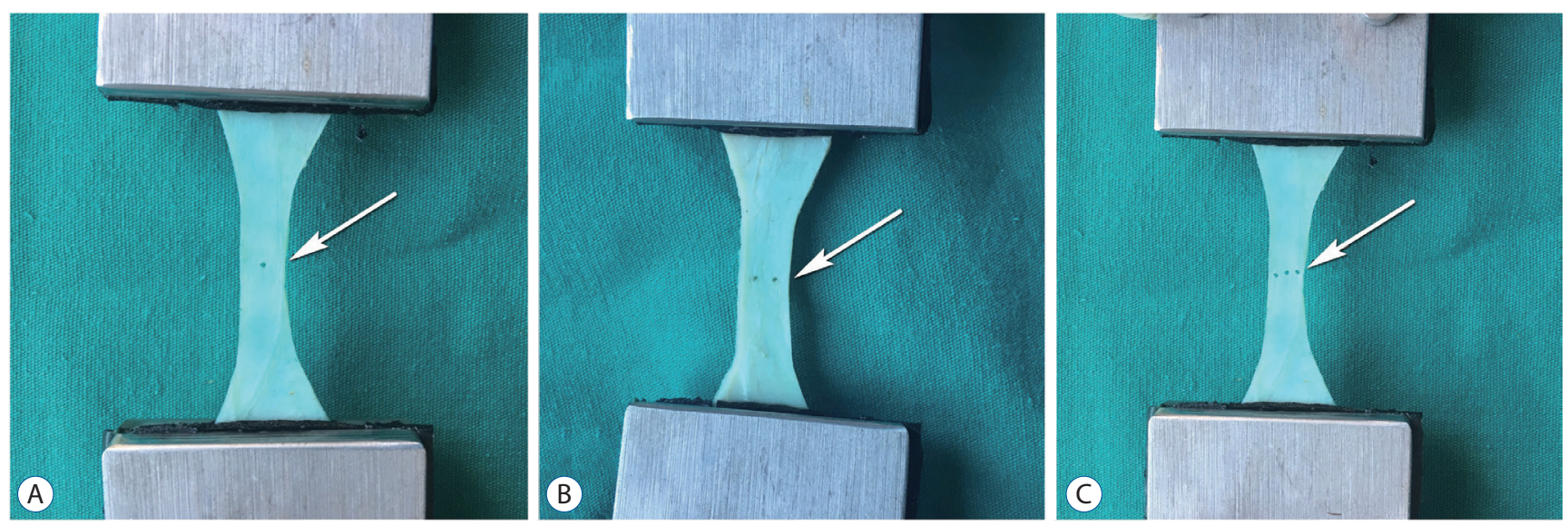

Fig. 3. Puncture defects before the uniaxial tension test. A : One-puncture defect (arrow). B : Two-puncture defects (arrow). C : Three puncture defects (arrow). 
study, $p<0.05$ was considered to be statistically significant.

\section{RESULTS}

Table 1 summarises the mean tensile strength, Young's modulus and thickness of the specimens used in this study. The mean maximum tensile strengths for groups I, II, III, and

Table 1. The mean values of thickness, maximum tensile strength and Young's modulus of human cranial dura mater in all the groups

\begin{tabular}{|c|c|c|c|c|c|c|}
\hline \multirow{2}{*}{ Group } & \multicolumn{2}{|c|}{ Thickness (mm) } & \multicolumn{2}{|c|}{ Tensile strength (MPa) } & \multicolumn{2}{|c|}{ Young modulus (MPa) } \\
\hline & $\mathrm{N}$ & $p$-value & $\mathrm{N}$ & $p$-value & $\mathbf{N}$ & $p$-value \\
\hline Group I (n=7) & $0.55 \pm 0.15$ & - & $8.35 \pm 3.16$ & - & $77.86 \pm 41.47$ & - \\
\hline Group II $(n=7)$ & $0.65 \pm 0.16$ & $0.272^{*}$ & $8.22 \pm 3.32$ & $0.749^{\dagger}$ & $73.34 \pm 30.84^{\ddagger}$ & $0.668^{\S}$ \\
\hline Group III (n=7) & $0.48 \pm 0.19$ & $0.261^{*}$ & $7.13 \pm 1.77$ & $0.482^{\dagger}$ & $71.59 \pm 12.67^{\ddagger}$ & $0.273^{\S}$ \\
\hline Group IV ( $n=7)$ & $0.57 \pm 0.19$ & $1^{*}$ & $6.94 \pm 1.93$ & $0.479^{\dagger}$ & $86.01 \pm 20.14^{\ddagger}$ & $0.670^{\S}$ \\
\hline
\end{tabular}

Values are presented as mean \pm standard deviation. The mean values of thickness, maximum tensile strength and Young's modulus of human cranial dura mater in all the groups. Statistical analyses were calculated with the Mann-Whitney U-test. Group I : dura mater specimen (control); group II : dura mater with one-puncture; group III : dura mater with two punctures; group IV : dura mater with three punctures. ${ }^{*} p$ values of mean specimen thickness of group II, III, and IV compared with group I. ${ }^{\dagger} p$ values of mean maximum tensile strength of group II, III, and IV compared with group I. "Young's modulus of some specimens could not be calculated because of low tensile strength. ${ }^{\S} p$ values of mean Young modulus of group II, III, and IV compared with group I
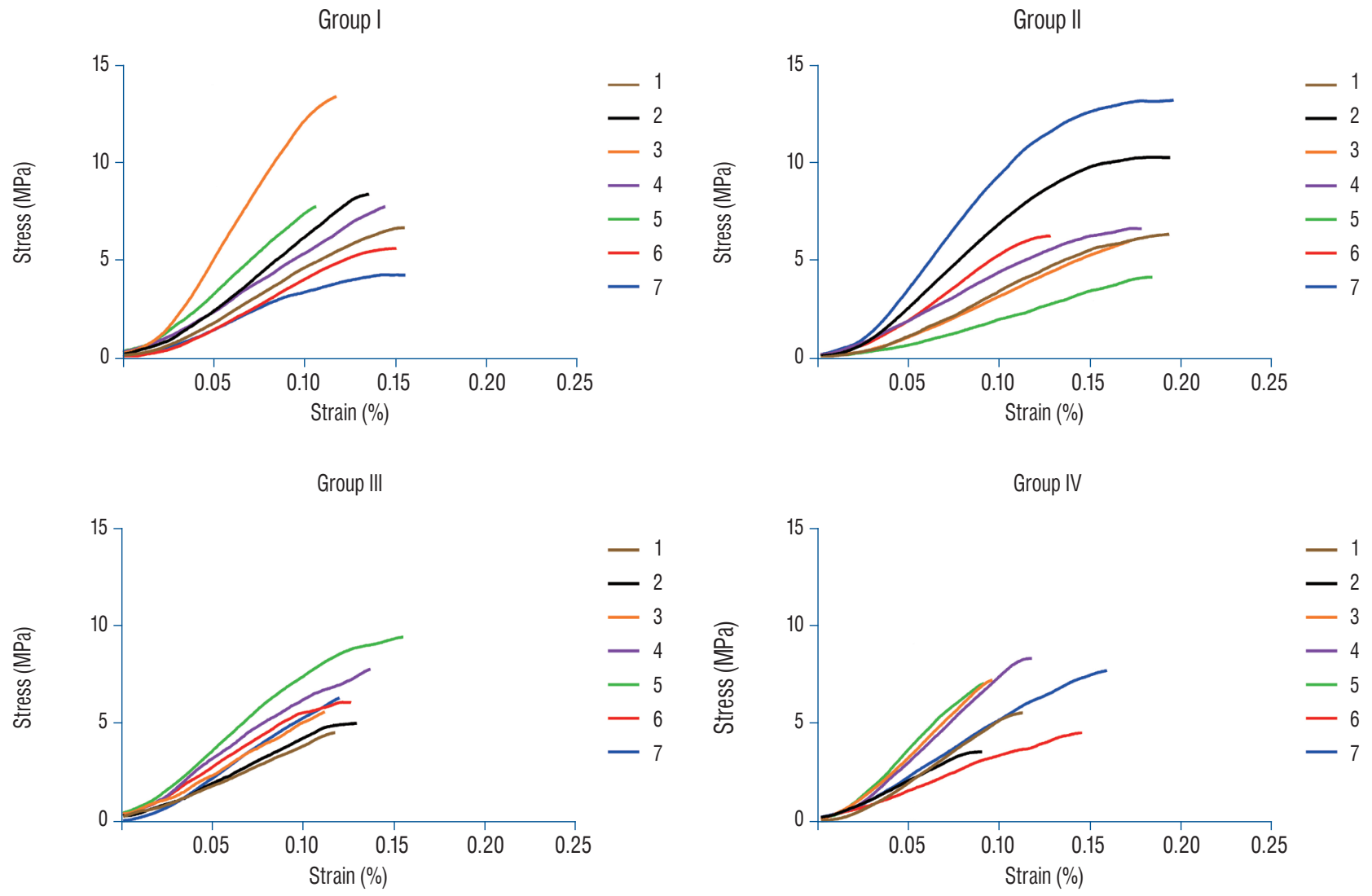

Fig. 5. This figure shows the curves resulting from the equations for the stress/strain ratio. Stress-strain curves for all groups $(n=28)$ with a displacement rate of 10 $\mathrm{mm} / \mathrm{min}$. 
IV were $8.35 \pm 3.16,8.22 \pm 3.32,7.13 \pm 1.77$, and $6.94 \pm 1.93 \mathrm{MPa}$, respectively. Fig. 5 shows the curves resulting from the equations for the stress/strain ratio. In addition, the mean Young's modulus for groups I, II, III, and IV were 77.86 $\pm 41.47,73.34 \pm$ $30.84,71.59 \pm 12.67$, and $86.01 \pm 20.14 \mathrm{MPa}$, respectively.

We observed a significant difference in the specimen thickness between groups II and III ( $p=0.024)$, but observed no significant difference in tensile strength among all the groups $(p>0.05)$. However, tensile strength in group IV was lower than that in group I, and no significant difference existed between groups I and IV in the displacement of the specimens during tension $(p=0.482$ ). Furthermore, we observed no significant difference in Young's modulus among all groups $(p>0.05)$. Notably, Young's modulus could not be calculated for one specimen of group II, three specimens of group III and two specimens of group IV.

\section{DISCUSSION}

As the human dura mater possesses both viscous and elastic properties, it is recognised as a viscoelastic material, which is an excellent shock absorber. In their study, van Noort et al. ${ }^{23)}$ evaluated the mean tensile strength of the human cranial dura mater as 4.70 $\mathrm{MPa}$. Likewise, Wolfinbarger et al. ${ }^{24)}$ reported that the mean tensile strength of the human cranial dura mater was 6.65 $\pm 0.14 \mathrm{MPa}$ and McGarvey et al. ${ }^{14)}$ reported that it was $9.41 \pm 1.54 \mathrm{MPa}$. In our study, the mean tensile strength in group I was 8.35 $\pm 3.16 \mathrm{MPa}$.

With regard to the mean Young's modulus of the human cranial dura mater, van Noort et al. ${ }^{23)}$ reported it to be 21.3-48 $\mathrm{MPa}$, Wolfinbarger et al. ${ }^{24)}$ reported it to be $69.50 \pm 1.28 \mathrm{MPa}$ and McGarvey et al. ${ }^{14)}$ reported it to be $61.50 \pm 9.60 \mathrm{MPa}$. In our study, the mean Young's modulus in group I was 77.86 $41.47 \mathrm{MPa}$. Of note, we could not evaluate Young's modulus in some groups because of low tensile strength.

Zerris et al. ${ }^{27)}$ reported that the mean tensile strength of Durepair $^{\circledR}$ (bovine collagen dural graft; Medtronic, Minneapolis, MN, USA) was 22.70 $\pm 2.83 \mathrm{MPa}$. Famaey et al. ${ }^{3)}$ compared the axial tension in stretchable and non-stretchable expanded polytetrafluoroethylene and reported values of $41.48 \pm 3.34$ $\mathrm{MPa}$ and 32.40土3.80 MPa for stretchable and non-stretchable, respectively. These studies explained that artificial dura mater substitutes were more durable than native human cranial dura mater. Our study supports the fact that the tissue biomechanical properties of novel dura mater graft materials differ from those of cranial dura mater. In the future, it is necessary to ensure that biomechanical properties of artificial graft material are similar to those of human dura mater when developing the new dura mater grafts.

Oh et al. ${ }^{16)}$ designed a novel microneedle array for the treatment of hydrocephalus and placed the implant on porcine dura mater in a way that it created channels for the flow of cerebrospinal fluid. The cone-shaped microneedle diameter was $0.05 \mathrm{~mm}$, which was pushed by a pressure gun to place the needle into the $0.3-\mathrm{mm}$ thick dura mater 16 . In our study, we used an automated insertion technique and constant velocity with a $20-\mathrm{G}(0.8 \mathrm{~mm})$ Quincke spinal needle to create puncture defects in the human cranial dura mater.

Comparing the Quincke needle bevel insertion parallel and perpendicular to the spinal dura mater, Reina et al. ${ }^{18)}$ observed no significant difference in the dura-arachnoid lesion created by the puncture. In addition, using the Quincke needle bevel insertion parallel to the spinal dura mater, Flaatten et al. ${ }^{5)}$ reported a low incidence of post-dural puncture headache. Of note, the parallel insertion did not cut, but separated the fibres, as illustrated by the longitudinal orientation of the spinal dura mater ${ }^{5)}$. Mihic ${ }^{15)}$ reported that the rate of post-dural puncture headache was lower when the bevel of the Quincke needle was inserted parallel to the spinal dura mater. Furthermore, in their investigation of microscopic structure, Reina et al. ${ }^{18,19)}$ determined no longitudinal orientation of the collagen and elastic fibres. Although human cranial dura mater possesses isotropic mechanical properties, we inserted the bevel of the Quincke needle parallel to the specimens to simulate the impact.

Reportedly, needle and tissue interaction can be affected by the insertion method (manual, automated, velocity, or direction of the bevel), needle type (Quincke, Sprotte, Tuohy conical, etc.) and tissue characteristics ${ }^{22)}$. Mahvash and Dupont ${ }^{12)}$ reported that the puncture force decreased with increasing velocity during needle insertion. In addition, Lewis et al.") investigated puncture forces on human dura mater and reported perpendicularly oriented higher puncture forces bevels. Lybecker et al. ${ }^{11)}$ reported no significant difference between postdural puncture headache and repeated dural puncture in samples of 1021 patients. However, Seeberger et al. ${ }^{21)}$ revealed that repeated dural punctures increased post-dural puncture 
headache in 8034 patients. While Kim and Yoon ${ }^{6}$ observed no significant difference in the results between $23 \mathrm{G}$ and $25 \mathrm{G}$ Quincke needle on lumbar puncture attempts, they reported an average of 1.4 lumbar puncture attempts for the $23 \mathrm{G}$ and 1.6 for the $25 \mathrm{G}$ Quincke needle; their success rate in the first attempt was $40 \%$ for the $25 \mathrm{G}$ Quincke needle.

In this study, we assessed the effects of one or more dural puncture(s) on dura mater biomechanics under uniaxial tension and observed no significant difference in the displacement of specimens during tension among the groups. In addition, single or multiple punctures exerted no adverse effect on cranial dura mater biomechanics under uniaxial tension, suggesting that single or multiple punctures of the dura mater using a $20 \mathrm{G}$ Quincke needle did not affect tensile stress. Furthermore, the tensile stress decreased in groups II, III, and IV compared to group I, but the difference was not statistically significant.

This study has some limitations. First, this study lacks specimens from children and various needle types to create puncture defects. During uniaxial testing, sample standardisation is imperative for soft tissue biomechanics. In addition, Young's modulus of the specimens could be affected by various factors, and storage conditions and duration are some of the factors that could affect tissue mechanics. In this study, we used frozen and thawed samples of the dura mater but did not investigate the impact of the freeze-thaw cycle on dura mater biomechanics. Finally, we did not assess age-related characteristics of the dura mater in this study. Thus, further extensive studies are warranted to overcome these limitations and validate the findings of this study.

\section{CONCLUSION}

This basic laboratory-based in vitro study is the first to illustrate the effects of puncture(s) on human cranial dura mater under stress tension. During surgery, every puncture or suture on the cranial dura mater could affect the mechanical properties of the dura mater, causing surgical failures in extreme cases. Artificial dura mater have been produced to substitute human dura mater. We also suture or make punctures on artificial dura mater during surgery. During artificial dura mater production, it is important that the substitute has properties that are biologically and biomechanically similar to hu- man dura. Thus, we believe that the present biomechanical study may contribute to the future development of artificial dura mater substitutes and medical needles that exert a relatively lower negative impact on dura mater

\section{CONFLICTS OF INTEREST}

No potential conflict of interest relevant to this article was reported.

\section{INFORMED CONSENT}

Informed consent was obtained from all individual participants included in this study.

\section{AUTHOR CONTRIBUTIONS}

\author{
Conceptualization : HEA, CK, AA \\ Data curation : HEA, CK, IK \\ Formal analysis : HEA, BH \\ Funding acquisition : HEA \\ Methodology : CK, BH \\ Project administration : CK, GS, HH \\ Visualization : AA, HEA \\ Writing - original draft : HEA, CK, IK \\ Writing - review \& editing: HEA, CK, IK, HH, AA
}

\section{- Acknowledgements}

The authors acknowledge the staff of the Dokuz Eylul University School of Medicine Health Science Institute Biomechanics Laboratory and Izmir Forensic Medicine Institution for their technical support in the completion of this study.

\section{References}

1. Davignon KR, Dennehy $K C$ : Update on postdural puncture headache. Int Anesthesiol Clin $40: 89-102,2002$

2. Dufrane D, Marchal C, Cornu O, Raftopoulos C, Delloye C : Clinical application of a physically and chemically processed human substitute for dura mater. J Neurosurg 98 : 1198-1202, 2003 
3. Famaey N, Verhoeven J, Jacobs S, Pettinari M, Meyns B : In situ evolution of the mechanical properties of stretchable and non-stretchable ePTFE vascular grafts and adjacent native vessels. Int J Artif Organs $37: 900-910,2014$

4. Flaatten $H$, Felthaus J, Kuwelker M, Wisborg T : Postural post-dural puncture headache. A prospective randomised study and a meta-analysis comparing two different $0.40 \mathrm{~mm}$ O.D. $(27 \mathrm{~g})$ spinal needles. Acta Anaesthesiol Scand 44 : 643-647, 2000

5. Flaatten $H$, Thorsen $T$, Askeland B, Finne M, Rosland J, Hansen T, et al. : Puncture technique and postural postdural puncture headache. A randomised, double-blind study comparing transverse and parallel puncture. Acta Anaesthesiol Scand 42 : 1209-1214, 1998

6. Kim M, Yoon H : Comparison of post-dural puncture headache and low back pain between 23 and 25 gauge Quincke spinal needles in patients over 60 years: randomized, double-blind controlled trial. Int J Nurs Stud 48 : 1315-1322, 2011

7. Lewis MC, Lafferty JP, Sacks MS, Pallares VS, TerRiet M : How much work is required to puncture dura with Tuohy needles? Br J Anaesth $85: 238-241,2000$

8. Liu SS, McDonald SB : Current issues in spinal anesthesia. Anesthesiology $94: 888-906,2001$

9. Longo $S$ : Postdural puncture: implications and complications. Curr Opin Anaesthesiol $12: 271-275,1999$

10. Lux EA, Althaus $A$ : Is there a difference in postdural puncture headache after continuous spinal anesthesia with $28 \mathrm{G}$ microcatheters compared with punctures with $22 \mathrm{G}$ Quincke or Sprotte spinal needles? Local Reg Anesth $7: 63-67,2014$

11. Lybecker H, Møller JT, May O, Nielsen HK : Incidence and prediction of postdural puncture headache. A prospective study of 1021 spinal anesthesias. Anesth Analg 70 : 389-394, 1990

12. Mahvash $M$, Dupont PE : Fast needle insertion to minimize tissue deformation and damage. IEEE Int Conf Robot Autom 2009 : 30973102, 2009

13. Matas SL: Why should we use atraumatic needles in lumbar puncture? Arq Neuropsiquiatr 71 : 681-684, 2013

14. McGarvey KA, Lee JM, Boughner DR : Mechanical suitability of glycerolpreserved human dura mater for construction of prosthetic cardiac valves. Biomaterials 5 : 109-117, 1984

15. Mihic DN : Postspinal headaches, needle surfaces and longitudinal orientation of the dural fibers. Results of a survey. Reg Anaesth 9 : 54-
56,1986

16. Oh J, Liu K, Medina T, Kralick F, Noh HM : A novel microneedle array for the treatment of hydrocephalus. Microsyst Technol $20: 1169-1179$, 2014

17. Protasoni M, Sangiorgi S, Cividini A, Culuvaris GT, Tomei G, Dell'Orbo C, et al. : The collagenic architecture of human dura mater. J Neurosurg 114 : 1723-1730, 2011

18. Reina MA, De Leon Casasola O, López A, De Andrés JA, Mora M, Fernández $A$ : The origin of the spinal subdural space: ultrastructure findings. Anesth Analg 94 : 991-995, table of contents, 2002

19. Reina MA, López-García A, Dittmann M, de Andrés JA : Analysis of the external and internal surface of human dura mater with scanning electron microscopy. Rev Esp Anestesiol Reanim 43 : 130-134, 1996

20. Schmittner MD, Urban N, Janke A, Weiss C, Bussen DG, Burmeister MA, et al. : Influence of the pre-operative time in upright sitting position and the needle type on the incidence of post-dural puncture headache (PDPH) in patients receiving a spinal saddle block for anorectal surgery. Int J Colorectal Dis 26 : 97-102, 2011

21. Seeberger MD, Kaufmann M, Staender S, Schneider M, Scheidegger D : Repeated dural punctures increase the incidence of postdural puncture headache. Anesth Analg 82 : 302-305, 1996

22. van Gerwen DJ, Dankelman J, van den Dobbelsteen JJ : Needle-tissue interaction forces--a survey of experimental data. Med Eng Phys 34 : $665-680,2012$

23. van Noort R, Black MM, Martin TR, Meanley $S$ : A study of the uniaxial mechanical properties of human dura mater preserved in glycerol. Biomaterials $2: 41-45,1981$

24. Wolfinbarger $L$ Jr, Zhang YX, Adam BLT, Homsi D, Gates K, Sutherland $V$ : Biomechanical aspects on rehydrated freeze-dried human allograft dura-mater tissues. J Appl Biomater 5 : 265-270, 1994

25. Yamada K, Miyamoto S, Nagata I, Kikuchi H, Ikada Y, Iwata H, et al. : Development of a dural substitute from synthetic bioabsorbable polymers. J Neurosurg 86 : 1012-1017, 1997

26. Yamada K, Miyamoto S, Takayama M, Nagata I, Hashimoto N, Ikada Y, et al. : Clinical application of a new bioabsorbable artificial dura mater. J Neurosurg $96: 731-735,2002$

27. Zerris VA, James KS, Roberts JB, Bell E, Heilman CB : Repair of the dura mater with processed collagen devices. J Biomed Mater Res B Appl Biomater 83 : 580-588, 2007 